\title{
Los ingenieros y la práctica de la arquitectura. La obra de Miguel de la Colina Puyol
}

\author{
Maite Paliza Monduate ${ }^{1}$
}

\begin{abstract}
RESUMEN
ABSTRACT

La rivalidad entre ingenieros $y$ arquitectos durante el siglo XIX como consecuencia de cambios en la legislación, que otorgó a los primeros prerrogativas que a lo largo del tiempo habian sido parcela exclusiva de los segundos, ha sido objeto de atención de numerosas publicaciones, que igualmente han

resaltado la intervención de los ingenieros en proyectos de ensanche, viaductos, estaciones de ferrocarril, etc. Sin embargo, son mucho menos conocidas, aunque de igual forma importantes, sus incursiones en el campo de la vivienda, donde destacó el ingeniero industrial Miguel de la Colina Puyol, que dejó magníficas obras en el municipio vizcaíno de Sopuerta.

The rivalry between engineers and architects in the 19th century, as a consequence of changes in legislation which gave engineers privileges that in the past had been exclusive domain of architects, has been the centre of attention of many publications. These publications have also emphasized the intervention of engineers in suburban development, viaducts, raillway stations, etc. However, much less well known, although equally important, are their incursions in the field of housing, where the outstanding industrial engineer, Miguel de la Colina Puyol, left splendid works, as can be seen in the Biscay municipality of Sopuerta.
\end{abstract}

A lo largo del siglo XIX tuvo lugar una viva polémica entre arquitectos e ingenieros, que afectó a todo el mundo occidental y a la que en el caso español se unió un tercer colectivo, el de los maestros de obras. En nuestro

1 Departamento de Historia del Arte de la Universidad de Salamanca. 
país los profesionales de la arquitectura gozaban de una situación privilegiada desde 1755, fecha en la que se les había concedido el título de nobleza personal y la libertad profesional, en una época en la que el ejercicio de cualquier actividad profesional suponía la incorporación laboral a gremios y hermandades ${ }^{2}$. Durante la primera parte de la centuria decimonónica, la profesión continuó adquiriendo prebendas y un enorme prestigio, pero en la segunda mitad esta especie de paraíso sufrió un notable menoscabo, debido a los cambios sufridos por la legislación, que en numerosas ocasiones favoreció sobremanera a los ingenieros y los maestros de obras con prerrogativas, que hasta entonces habían sido privativas de los arquitectos. No obstante, este conflicto se había manifestado con distintos altibajos desde los primeros años del siglo, concretamente desde la fundación de la Escuela de Ingenieros de Caminos y Canales por Agustín Betancourt en $1802^{3}$. Posteriormente, la creación del cuerpo de Ingenieros Civiles en 1835 supuso que el campo de las obras públicas fuera parcela exclusiva de los ingenieros, quienes por esta circunstancia recibieron entre otras cosas los encargos de ensanche de las ciudades, de modo que los arquitectos vieron sensiblemente recortadas sus competencias en una parcela especialmente sustanciosa en emolumentos pecuniarios ${ }^{4}$. Este complicado trasfondo tal vez fuera una de las posibles motivaciones, que indujera a algunos técnicos destacados de la época a conseguir la doble titulación de arquitecto e ingeniero (Alberto Palacio Elissague, Leonardo Rucabado, etc.).

La paulatina especialización, la utilización de modernos materiales en el mundo de la construcción, la aparición de nuevas tipologías arquitectónicas (estaciones de ferrocarril, viaductos, mercados, etc.) favorecieron notablemente la incursión de los ingenieros en el campo de la arquitectura a medida que avanzaba el siglo XIX e incluso en el Xx. Esto último fue muy evidente en el caso de los viaductos, puentes, estaciones de ferrocarril, fábricas y pabellones industriales y este colectivo aún tuvo un papel ciertamente notorio en el caso de los mercados ${ }^{5}$. No obstante,

\footnotetext{
2 DIez de Baldeon, C.: Arquitectura y clases sociales en el Madrid del siglo XIX. Siglo XXI. Madrid, 1986, pág. 86.

3 Vid. datos respecto a esta polémica en MiRanda Regojo, F.: El problema profesional: Ingeniería/Arquitectura. En BONET CORREA y otros: La polémica Ingenieros-Arquitectos en España. Siglo XIX. Colegio Oficial de Ingenieros de Caminos, Canales y Puertos y Ediciones Turner. Madrid, 1985 , págs. $77-132$.

${ }^{4}$ En este sentido vid.: Antigüedad del CAstillo-Olivares, M.D.: Los ingenieros urbanistas en la España decimonónica. Rev. Espacio, Tiempo y Forma. Serie VII, $H_{.}{ }^{a}$ del Arte, t. 10, 1997, págs. 217-236.

5 En este sentido vid. entre otros NAVAscues Palacio, P.: Arquitectura española (1808-1814). T. XXV* Summa Artis. Espasa Calpe. Madrid, 1993.
} 
son menos conocidas y apenas si han sido estudiadas o resaltadas sus aportaciones al campo de la arquitectura doméstica, especialmente en lo relativo a la vivienda unifamiliar ${ }^{6}$, sobre todo fuera de las grandes poblaciones, donde la aplicación de la normativa, que reservaba esta parcela para los arquitectos y los maestros de obras, fue menos rigurosa. Precisamente esta fue la tipología en la que destacó de forma magistral el ingeniero Miguel de la Colina, objeto central del presente estudio.

Respecto a la frecuencia con la que estos profesionales hicieron incursiones en la arquitectura residencial, puede ilustrar la circunstancia de que en el pequeño ámbito de Las Encartaciones (Vizcaya), al que también corresponden las obras aquí recogidas, hay al menos otros dos casos. Son los de Urbano Peña Chávarri, ingeniero de Caminos, Canales y Puertos ${ }^{7}$, activo en el municipio de Carranza, donde dejó abundante producción, promovida por su propia familia, incluida una iglesia - lo que posiblemente sea un caso único en España- ${ }^{8}$, y José Bretones Calderón ${ }^{9}$, afincado en Lanestosa, de quien tenemos constancia que proyectó alguna residencia en esta localidad.

Por lo que se refiere a Miguel de la Colina Puyol, nació a las seis de la mañana del día diez de diciembre de 1885 en el municipio vizcaíno de Sopuerta. Era hijo de José María de la Colina Moncalián (1845-1929), natural de la villa encartada de Lanestosa, y de Ramona Puyol Arnaiz, nacida en Sopuerta. Pertenecía a una familia muy vinculada al ejercicio

6 Por lo que se refiere a la cornisa cantábrica apenas si contamos con noticias publicadas respecto a una decena de proyectos. En el caso cántabro, Luis Sazatornil tan sólo registra una residencia en su tesis doctoral. En concreto, la Quinta Las Carolinas, debida al ingeniero Alberto Corral Alonso de la Fuente, mientras que en el ámbito asturiano Covadonga Álvarez recoge cinco obras atribuidas a ingenieros, aunque arroja serias dudas sobre la autoría de alguna de ellas. (En este sentido vid. Álvarez QuINTANA, C.: Indianos y arquitectura en Asturias 1870-1930. (T. I). Colegio Oficial de Aparejadores y Arquitectos Técnicos de Asturias. Gijón, 1991, págs. 475 y 476 y SAZATORNIL Ruíz, L.: Arquitectura y desarrollo urbano de Cantabria en el siglo xix. Universidad de Cantabria, Colegio Oficial de Arquitectos de Cantabria y Fundación Marcelino Botín. Santander, 1996, pág. 286.)

7 Respecto a las obras públicas de este ingeniero, la bibliografía existente en la actualidad recoge el dato de su intervención en un puente de 105 metros de longitud en la línea de ferrocarril que une León con Orense, proyectado en colaboración con el inglés M. Richard en 1883. En este sentido vid. Navascues Palacio, P.: Op. cit., pág. 402.

8 Vid. un análisis de alguna de las aportaciones de este ingeniero al campo de la arquitectura doméstica en PALIzA MONDUATE, M.: La arquitectura residencial en Carranza desde finales del siglo XIX hasta mediados del siglo $\mathrm{xx}$. Cuadernos de Sección Artes Plásticas y Monumentales Sociedad de Estudios Vascos (San Sebastián). N. 7 (1990), págs. 55-63.

9 José Bretones Calderón, nacido en Cartagena (Murcia), era ingeniero de minas. Afincado en Lanestosa en 1880, fue director de las explotaciones mineras de esta localidad desde ese año hasta finales del siglo XIX, momento en que junto a su familia se instaló en Santander. Durante su estancia en esta villa vizcaína, algunos nestosanos le encargaron el proyecto de sus residencias. 


\section{MAITE PALIZA MONDUATE}

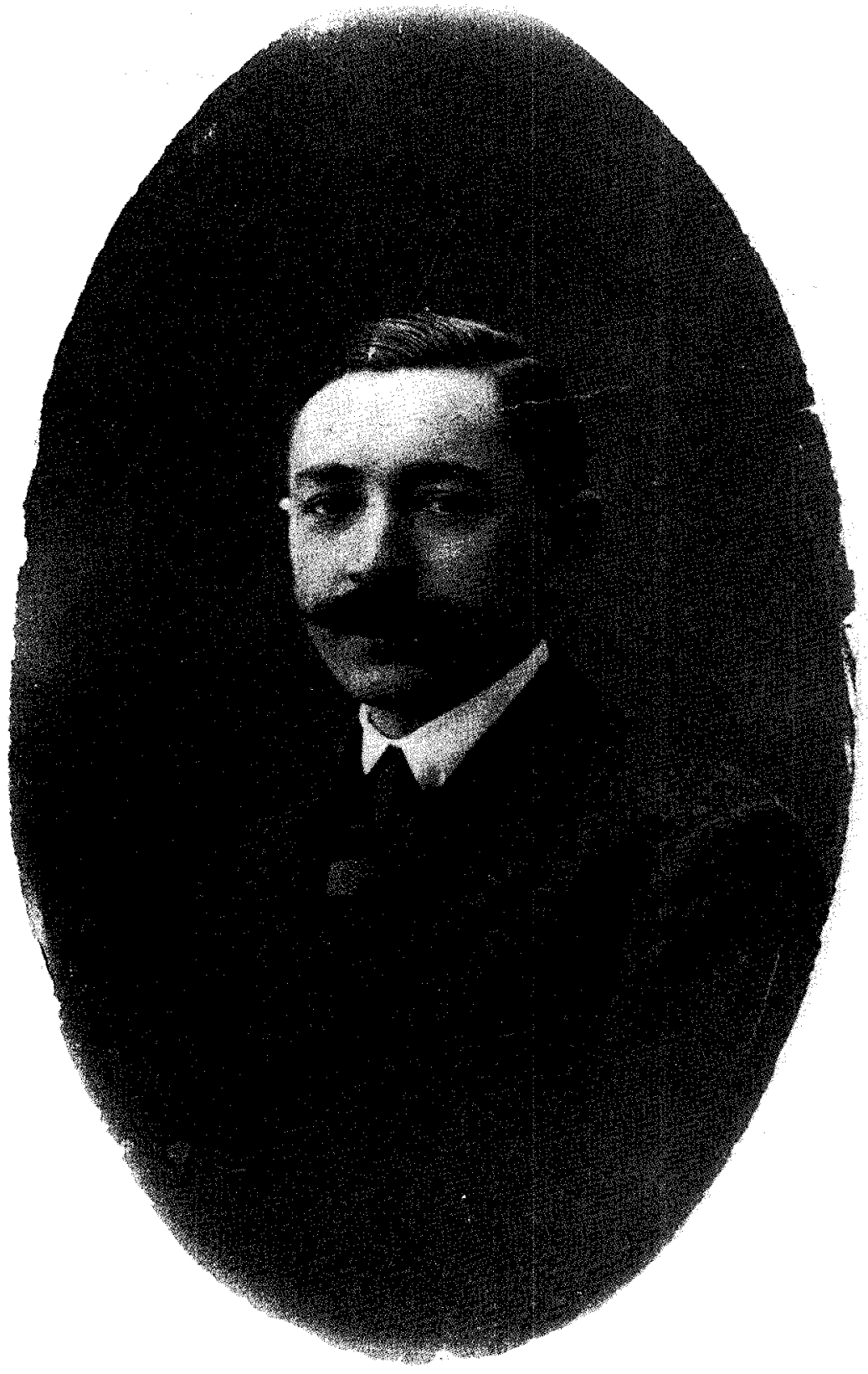

Fig. 1. El ingeniero industrial y farmacéutico Miguel de la Colina. 
de la profesión de farmacéutico, ya que su bisabuelo Manuel Arnaiz, burgalés de nacimiento, ejerció como tal en Gordejuela. Su padre, que se había titulado en 1872, era propietario de la botica de Sopuerta, donde previamente su abuelo materno Carmelo Puyol, nacido en Valencia, también había sido boticario, así como su tío Isaac Puyol Arnaiz (1842-1873, titulado en 1867) ${ }^{10}$. Precisamente el temprano fallecimiento de este último motivó que José María de la Colina (titulado en 1872) se estableciera en Sopuerta, donde acabó emparentando matrimonialmente con la familia que había regentado la botica local durante muchos años.

Miguel de la Colina realizó sus primeros estudios en la escuela pública de su pueblo natal, donde tuvo por maestro a Homobono Domínguez, figura muy recordada en la localidad, después cursó el bachillerato en el por entonces prestigioso Colegio de los Jesuitas de Orduña y, más tarde, superó las pertinentes pruebas de convalidación en el Instituto Provincial de Vizcaya en Bilbao, donde obtuvo la oportuna titulación en 1904. Posteriormente continuó su formación en la Escuela de Ingenieros Industriales de Bilbao, donde realizó los exámenes de reválida el veinte de diciembre de 1913. En este centro adquirió conocimientos en materias afines al mundo de la arquitectura, toda vez que, como queda dicho, la normativa de la época facultaba a los ingenieros para proyectar determinado tipo de obras. De hecho, se conservan los planos de una Fábrica de hilaturas, que seguramente correspondían a un ejercicio de alguna asignatura, pues están marcados con el número dos, fechados el veinte de noviembre de 1910 y en ellos consta la firma ilegible de un profesor, que actuaba como secretario ${ }^{11}$. Con su título recien estrenado y dispuesto a comenzar el ejercicio de su profesión, un drama familiar vino a cambiar su trayectoria, ya que al fallecer su hermano Justo de la Colina Puyol (1880$1915^{12}$, titulado en $1902{ }^{13}$ ), que era licenciado en farmacia, Miguel decidió cursar esta última licenciatura para continuar la tradición familiar y acompañar a su progenitor, que por entonces aún regentaba una de las boticas de la localidad de Sopuerta.

De cara a la realización del curso preparatorio de las carreras de Ciencias, el diez de octubre de 1915 De la Colina solicitó que se le convalidaran una serie de asignaturas, que previamente había cursado y

10 Saratxaga Garal, A.: Catálogo de farmacias tradicionales de Bizkaia. Fundación BBK. Bilbao, 1998, pág. 345.

A.P.J.C.M.: Planos varios S.C.

12 Saratxaga Garal, A.: Op. cit, pág. 335.

13 A.P.J.C.M.: Documentos varios S.C. 


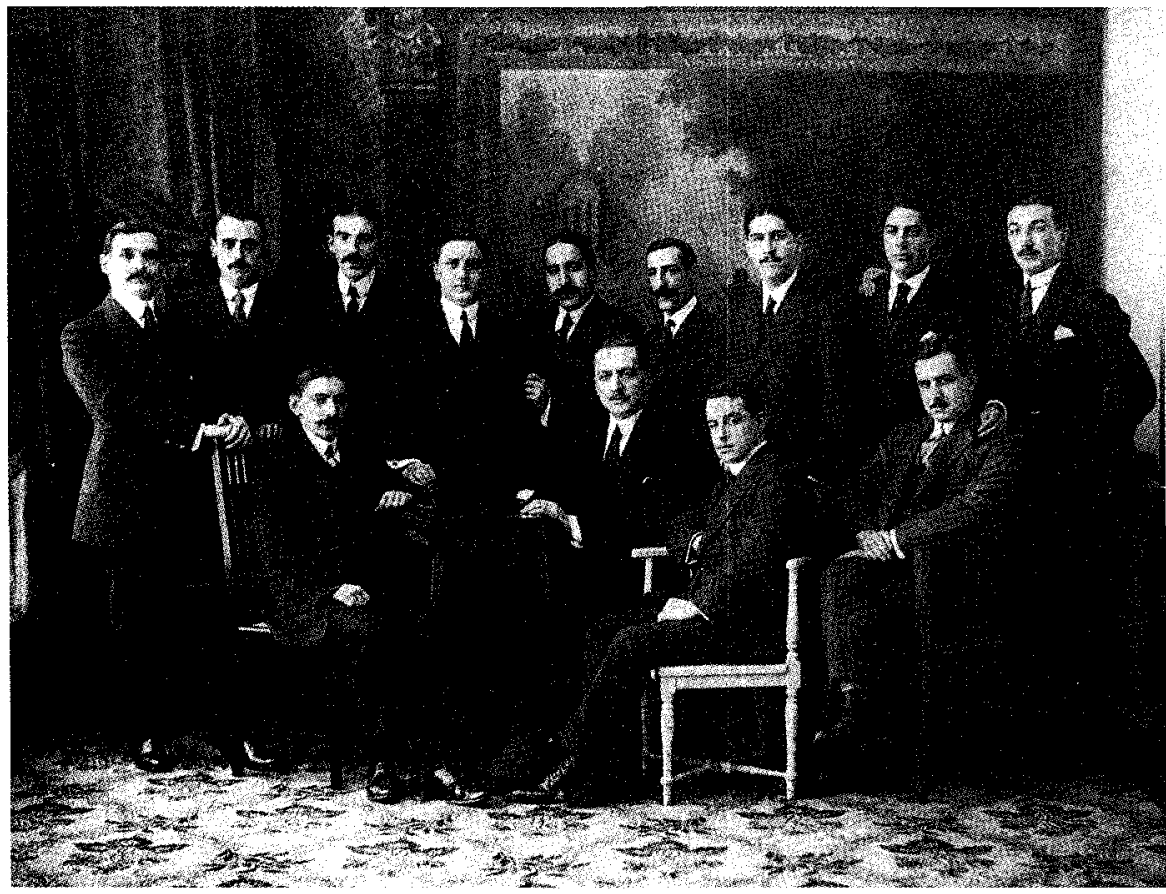

Fig. 2. Miguel de la Colina con sus compañeros de promoción de la Escuela de Ingenieros Industriales de Bilbao.

aprobado en la Escuela de Ingenieros Industriales de Bilbao. No obstante, su petición fue denegada en casi todos los puntos con el argumento de que los programas de las materias no coincidían y que la escuela bilbaína no dependía del estado. Así las cosas, realizó por libre el curso de ingreso a ciencias en la Universidad de Oviedo en el año académico 1914-1915, en el que tan sólo le fue convalidada la asignatura de Física General. Posteriomente realizó sus estudios de farmacia como alumno libre en las Universidades de Barcelona y Madrid y, finalmente, concluyó la licenciatura en la de Santiago de Compostela, donde fue expedido el correspondiente título el siete de mayo de $1919^{14}$. Desde entonces se dedicó principalmente a regentar la farmacia familiar en Sopuerta en un momento, en el que este municipio aún se beneficiaba de la afluencia de población derivada de las importantes explotaciones mineras de hierro

14 A.G.A.E.A.H.: Caja AGA 15.558. (Todos los datos referentes a la formación académica de Miguel de la Colina Puyol, a los que hemos hecho referencia proceden de esta documentación). 
allí existentes, con las que la familia materna del personaje que nos ocupa había tenido relación, ya que el citado Isaac Puyol llegó a registrar las minas Carmelo y Encarnación en 1871 y 1873 respectivamente ${ }^{15}$.

Dos años después de concluir sus estudios de farmacia, el 20 de abril de 1921, Miguel de la Colina contrajo matrimonio con Avelina Menéndez Cofiño en Zalla (Vizcaya). No tuvieron hijos, pero adoptaron a un sobrino y ahijado de la esposa, Javier de la Colina Menéndez, con quien habían tenido trato muy estrecho desde su más tierna infancia y que hoy perpetúa la vinculación de la familia al mundo de la farmacia, pues es titular del establecimiento de Sopuerta.

El protagonista de nuestro estudio era de carácter apacible y serio, directo en el trato pues no le gustaban los ambajes y católico practicante. Tuvo numerosas aficiones que iban desde la lectura a la práctica de diversos deportes como el montañismo, la natación, la caza - tanto de liebre, zorro, lobo e incluso rebeco en los Picos de Europa- y la pelota de pala corta, así como la horticultura y la carpintería, que dada la calidad y la naturaleza de los trabajos que realizó en este último campo más bien habría que hablar de ebanistería.

Hombre activo por naturaleza, una de las numerosas facetas en las que se manifestó su rica personalidad fue su colaboración en la prensa escrita. En concreto, a lo largo de la década de los sesenta y comienzo de los setenta, publicó artículos breves en el periódico El Oriente de Asturias, decano de la prensa asturiana. Estos escritos ratifican la diversidad de sus intereses, puesto que algunos de ellos ponen de manifiesto su negativa a admitir la existencia de vida fuera de nuestro planeta ${ }^{16}$ y las teorías evolucionistas de Darwin ${ }^{17}$, mientras que otros corroboran sus profundas convicciones religiosas ${ }^{18}$, sus preocupaciones sociales, especialmente en lo relativo a las condiciones de vida de la población que emigraba del campo a la ciudad ${ }^{19}$, y sus intereses ecologistas ${ }^{20}$. Estas inquietudes periodísticas le llevaron a intentar publicar una crónica en el prestigioso rotativo londinense The Times,

\footnotetext{
15 Debo estos datos concretos sobre la vinculación de los Puyol con las minas de Sopuerta a Garbiñe Aja Santisteban.

16 DE LA COLINA, M.: ¿Existen en otros planetas hombres como nosotros? El Oriente de Asturias (Llanes). N. ${ }^{\circ} 18$ de abril de 1964; Platillos volantes. El Oriente de Asturias (Llanes). N. 28 de septiembre de 1968 y Los ovnis. El Oriente de Asturias (Llanes). N. 3 de mayo de 1969.

17 Ibídem: El limo-homo y el pitecantropus. El Oriente de Asturias (Llanes). N. ${ }^{\circ} 16$ de diciembre de 1967 y La vida en nuestro planeta. El Oriente de Asturias (Llanes). N. ${ }^{\circ} 29$ de marzo (1969).

18 Ibídem: Cristo ha resucitado. El Oriente de Asturias (Llanes). N. ${ }^{\circ} 28$ de marzo de 1970.

19 Ibídem: El obrero y la empresa. El Oriente de Asturias (Llanes). N. ${ }^{\circ} 25$ de agosto de 1962 y $\mathrm{E} \mid$ campo se despuebla. El Oriente de Asturias (Llanes). N. ${ }^{\circ} 29$ de octubre de 1966.

20 Ibídem: Riqueza forestal. El Oriente de Asturias (Llanes). N. ${ }^{\circ} 8$ de junio de 1963.
} 
casi como un intento de desagravio de la sociedad española ante algunas informaciones aparecidas en dicho medio ${ }^{21}$.

Otros trabajos redactados por Miguel de la Colina vieron la luz en revistas especializadas en farmacia. En Memoria de la inspección farmacéutica municipal de Sopuerta recogía brevemente su trayectoria y sus experiencias en el desempeño del cargo de inspector municipal de farmacia ${ }^{22}$, y en La Farmacia a través de cincuenta años de ejercicio en la profesión aludía a los cambios que se habían producido en el desempeño de su trabajo a principios de los sesenta por la creciente burocracia, que poco a poco iba convirtiendo a los titulares en meros gestores, al tiempo que denunciaba la ausencia en aquella época de seguros de vejez para los farmacéuticos, lo que había ocasionado algunas situaciones lamentables ${ }^{23}$.

Su dedicación prioritaria a las labores de farmacéutico, no fue impedimento para que en su condición de ingeniero realizara una serie de proyectos arquitectónicos y obras de ingeniería. Entre los primeros, que constituyen el principal objeto de nuestra atención, cabe citar su opera prima. La remodelación del edificio del barrio soportano de La Baluga, que había promovido a principios de siglo su padre, José María de la Colina Moncalián, para que acogiera el establecimiento de farmacia regentado por su hermano Justo de la Colina. Era una sencilla construcción de planta rectagular, cuyo único detalle destacable era un mirador, elemento muy característico de la arquitectura de la época, que estaba alineado con la entrada a la botica. Tras el fallecimiento de Justo de la Colina, este edificio, que había sufrido un incendio en diciembre de 1914, permaneció vacio hasta que, tras la boda de Miguel de la Colina, pasó a ser la vivienda de toda la familia Colina, por lo cual en torno a 1922 el ingeniero amplió y reformó la casa, que acabó teniendo una planta en $L$ y una galería dispuesta en el ángulo que forman los dos brazos del edificio. En los bajos del inmueble estaba la botica, que a partir de ese momento fue el único establecimiento farmacéutico de Sopuerta, donde a principios de siglo había tres farmacias, la de José María de la Colina en el barrio de Mercadillo y las de Barandiarán y Justo de la Colina en La Baluga ${ }^{24}$.

21 Testimonio de Javier de la Colina Menéndez, a quien desde estas líneas expreso mi agradecimiento por su inestimable colaboración.

22 De la Colina, M.: Memoria de la inspección farmacéutica municipal. La Farmacia Vizcaína (Bilbao). N. 2 (1957), págs. 21-24.

23 Ibídem: La farmacia a través de cincuenta años de ejercicio en la profesión. Farmacia Nueva (Madrid). N. ${ }^{\circ}$ XXVII (1962), págs. 148 y 149.

24 Ni el Archivo Municipal de Sopuerta ni el del Registro de la Propiedad de Balmaseda contienen documentación sobre el proyecto y las reformas de esta casa, por lo que para datarla sólo contamos con el testimonio de Javier de la Colina Menéndez. 
Tras esta opera prima, en fechas próximas a 1930, Colina llevó a cabo dos importantes reformas de antiguas casas para transformarlas en residencias de dos familias de la localidad, con las que le unían estrechos lazos de amistad ${ }^{25}$, motivo por el cual realizó ambos proyectos de forma gratuita. Estas viviendas han sido recogidas en diversas publicaciones, que han resaltado su interés y su relevancia dentro de la arquitectura contemporánea de la zona ${ }^{26}$, aunque en ningún caso han sido estudiadas y nunca hasta ahora se había indicado la intervención de un ingeniero industrial en el diseño de las mismas. En primer lugar acometió la remodelación de una vieja construcción para convertirla en residencia de verano del matrimonio formado por Paula San Martín, nacida en Sopuerta, y Ubaldino Hierro, natural de Mioño (Cantabria) e indiano que tras hacer fortuna en América se había afincado en Madrid. La familia San Martín, que se había enriquecido gracias a inversiones bursátiles, fue la que costeó la reforma del edificio ${ }^{27}$, que es conocido como Casa de Hierro, debido al apellido que prevaleció vía masculina. Establecidos en la capital de España, solían pasar los períodos vacacionales en la localidad encartada, circunstancia por la cual decidieron reformar una modesta casa y la finca circundante - que pertenecían a la familia desde principios del siglo xx ${ }^{28}$ en el barrio soportario de La Baluga.

De acuerdo con la opinión de algunas personas que presenciaron las obras de reforma, el antiguo inmueble, que databa de 1898 y había sido promovido por Lázaro Mendizábal Fuica ${ }^{29}$, no contaba con elementos de interés y apenas si fue respetado por el ingeniero que nos ocupa a la hora de concebir la reforma, de modo que casi podemos hablar de un proyecto de nueva planta. La remodelación tuvo lugar al final de la década de los veinte entre 1928, fecha en la que se tramitó la licencia de obras ${ }^{30}, y$ 1930 , momento de la conclusion de los trabajos de construcción ${ }^{31}$.

25 Las escasas noticias publicadas hasta ahora respecto a la intervención de ingenieros en la tipología de la vivienda unifamiliar coinciden en señalar una relación de parentesco, amistad e incluso vecindad entre el tracista y el comitente previa a la realización del proyecto. En este sentido, lo dicho al comienzo de este artículo sobre el ámbito encartado no es una excepción.

26 ETXABe Oribe, I.: Monografías de pueblos de Bizkaia. Sopuerta. Diputación Foral de Bizkaia. Bilbao, 1997, págs. 161 y 162 y VV.AA.: Bizkaia. Arqueología, urbanismo y arquitectura histórica (T. III). Diputación Foral de Bizkaia y Universidad de Deusto. Bilbao, 1991, pág. 548.

27 La documentación de los archivos del Registro de la Propiedad de Balmaseda y de Vidrieras de Arte corroboran este hecho.

28 En 1901, Pablo San Martín Puerto había cedido la mitad de esta finca a Ubaldino Hierro. (A.R.P.B.: Libro 342 Sopuerta, f. 62 v.).

29 A.R.P.B.: Libro 342. Sopuerta, f. 62 v.

30 A.P.J.C.M.: Documentos varios S.C.

31 Testimonio de Nieves Alonso Nocedal, testigo presencial de las obras de construcción. 
Miguel de la Colina ideó una vivienda de planta baja y dos pisos altos, además de una cuarta altura en el cuerpo de la torre angular. En el piso inferior, un porche comunica con el hall, que cuenta con un rincón con chimenea y el arranque de la escalera y reparte el paso al salón, el comedor, el despacho, la cocina, la despensa y un lavabo, mientras que las plantas superiores tienen una distribución similar con un gran hall rectangular, en el que desemboca la escalera y comunica con seis dormitorios, un baño y una sala, orientada hacia la fachada principal.

La distribución concebida por el ingeniero sigue los modelos al uso en la arquitectura unifamiliar de la cornisa cantábrica y de gran parte de España en ese momento, de los que el artífice demostró ser un gran conocedor. Esto resulta especialmente evidente en lo referente al hall de la planta baja tanto por las notables dimensiones, que lo convierten más en una zona de estar que en un sector de paso, como por la importancia de la decoración, que comentaremos más adelante. Esta concepción deriva claramente de los trazados aparecidos en Inglaterra en el siglo XIX, donde esta habitación se convirtió en el auténtico centro y corazón de la casa, ya que unía los diversos ámbitos de la vivienda y además recibía el tráfico de personas del exterior. En esta ocasión Miguel de la Colina lo dotó de un rincón con hogar, que inequívocamente procede de los llamados inglenooks victorianos. Estos eran una especie de pequeña habitación de poca altura y reducida superficie, dispuesta dentro de otra dependencia. Básicamente eran una minúscula zona de estar habilitada en torno a una chimenea. En el caso que nos ocupa, las dimensiones no permitían disponer sofás o sillas dentro del inglenook, pero la relación con los modelos británicos es indudable. El ingeniero industrial demostró, como queda dicho, un gran conocimiento de la organización de la arquitectura residencial vizcaína del momento, pues si bien en Inglaterra este tipo de rincones eran propios de los comedores, en Vizcaya fueron característicos del hall ${ }^{32}$.

Dados los parámetros actuales, puede resultar llamativo el elevado número de alcobas, puesto que, como hemos anticipado, se trataba de una casa concebida desde el primer momento para vacaciones y además el matrimonio Hierro sólo tenía dos hijos, pero el trazado respondía a unos modos de vida que no son los actuales, de modo que esta organización era usual en aquella época y además muy frecuente entre las residencias promovidas por indianos.

32 En este sentido vid. Paliza Monduate, M.: Manuel Maria de Smith Ibarra. Arquitecto. 1879 1956. Diputación Foral de Bizkaia. Salamanca, 1988, págs. 518 y ss. 


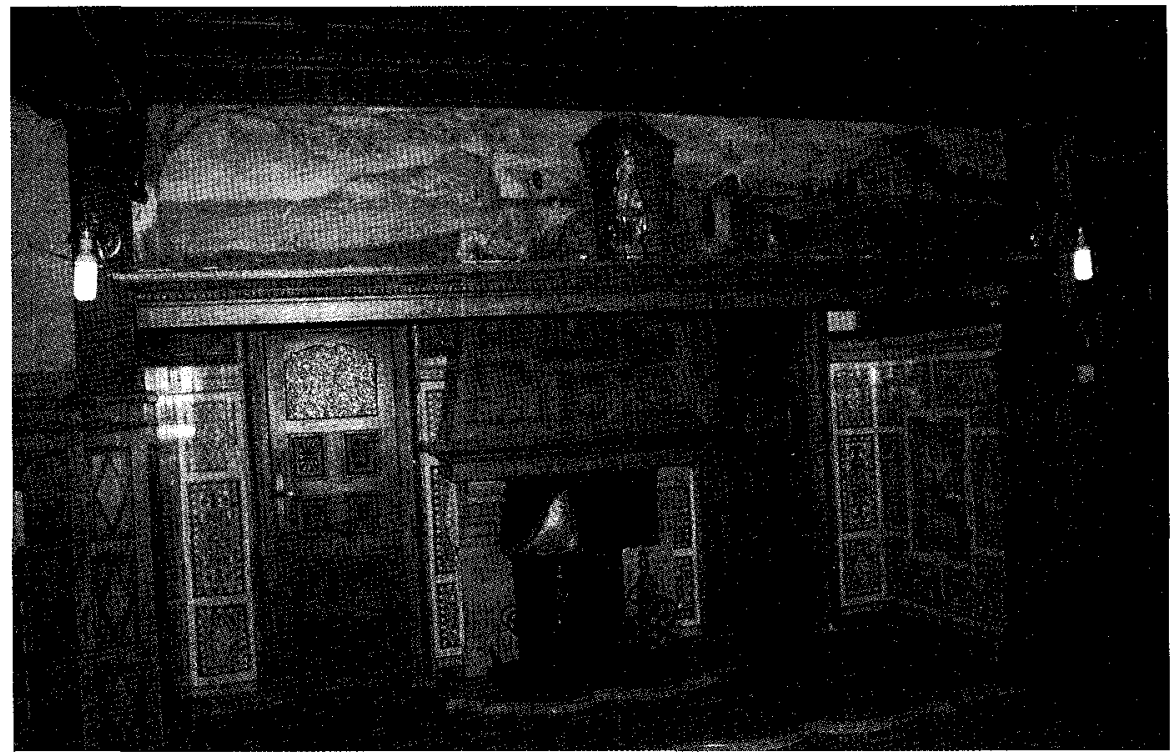

Fig. 3. Inglenook del hall de la casa de la familia Hierro.

Por lo que se refiere al alzado, la volumetría cúbica con torreón cuadrangular dispuesto en ángulo remite inequívocamente a modelos regionalistas de la llamada arquitectura montañesa, pero en contraposición los paramentos revocados y el empleo generalizado de entramados de madera ficticios en la parte alta de las fachadas no son propios de esta formulación arquitectónica, ideada por el arquitecto Leonardo Rucabado ${ }^{33}$ a partir de las formas de la arquitectura popular y de las casonas cántabras de los siglos XVI, XVII y XVIII, y más bien parecen estar en relación con otros regionalismos o con arquitecturas foráneas. En contraposición, la galería de la torre con triple arco de medio punto y las decoraciones que simulan recortes bajo su mirador, el alero de gran vuelo, la terraza angular del primer piso o las columnas de algunos vanos de la fachada principal, incluido el acceso al porche, entroncan plenamente con el estilo montañés.

Miguel de la Colina dedicó especial atención a la configuración de las ventanas, que ofrecían en los planos un gran número de soluciones

33 En este sentido vid. BASURto FERro, N.: Leonardo Rucabado y la arquitectura montañesa. Colegio Oficial de Arquitectos de Cantabria y Xarait. Bilbao, 1986 y ORDIERES DiEZ, I.: El álbum de apuntes de Leonardo Rucabado. Xarait. Bilbao, 1987. 


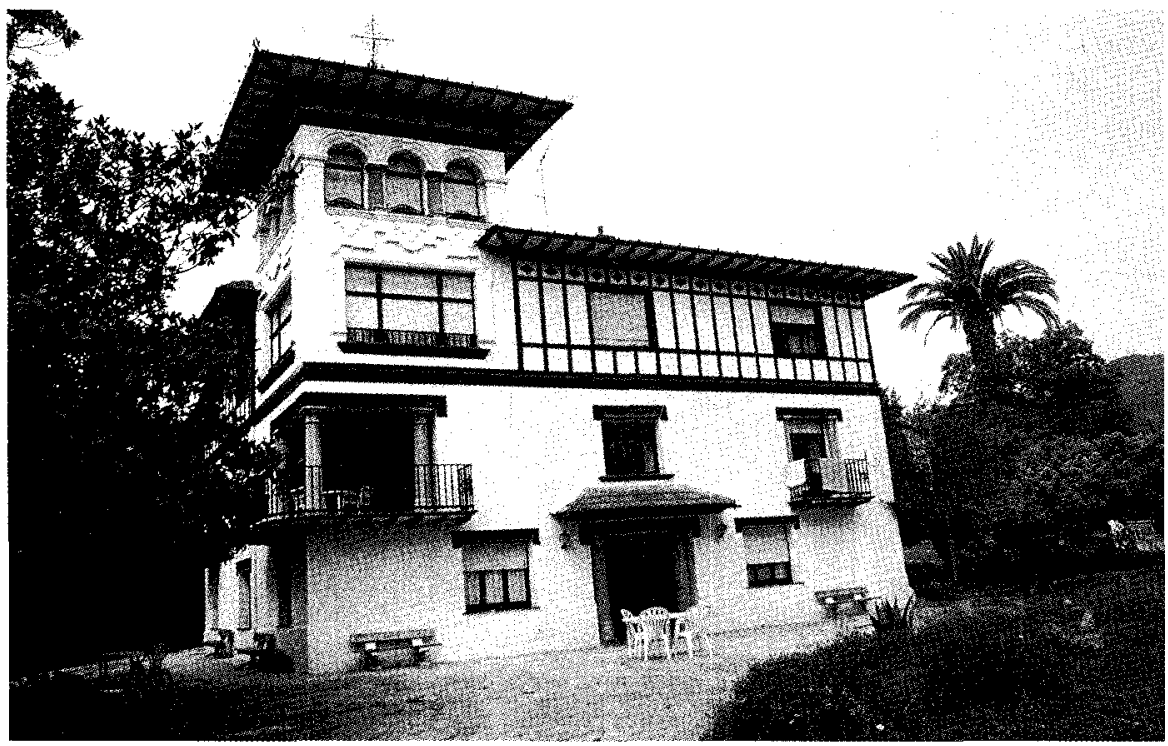

Fig. 4. Fachada principal de la casa de la familia Hierro.

(guillotina, bisagra, con paneles fijos en la parte superior, etc.), circunstancia que, al igual que la tendencia a subdividir la parte superior de las misimas por un gran número de montantes, fue frecuente en la arquitectura unifamiliar de la época y por lo tanto en el regionalismo montañés. Las labores de rejería (veleta con forma de cruz y antepechos de los balcones) también fueron diseñadas por el ingeniero.

Todo ello está en consonancia con la importancia de la casa, aunque la composición de la fachada principal se resiente de cierta desproporción respecto a las estilizadas volumetrías al uso en los edificios del regionalismo montañés. Dentro de la innegable calidad del inmueble es esta cuestión la que más claramente delata la intervención en el proyecto de un artífice ajeno al mundo específico de la arquitectura, ya que, aunque con mucha frecuencia los ingenieros pusieron especial empeño y atención en el diseño arquitectónico y cuajaron obras de gran nivel, normalmente siempre hay carencias y detalles concretos, especialmente en lo ornamental que ponen de manifiesto la condición de sus artífices. No obstante, también hay que tener presente que en este punto concreto Miguel de la Colina pudo estar en parte mediatizado por las dimensiones del edificio previo. Por lo demás, la fecha de la reforma, realizada avanzada ya la década de los veinte, puede explicar ciertas licencias respecto a los modelos prototípicos firmados por Rucabado antes de su fallecimiento en 1918. Sin embargo, esta última circunstancia no 
es imputable exclusivamente a la condición de ingeniero del proyectista, ya que planteamientos similares están presentes en obras ideadas por arquitectos seguidores del adalid de la arquitectura montañesa en fechas próximas a 1930, cuando el estilo había degenerado notablemente.

La decoración es uno de los aspectos más llamativos de la casa de los Hierro, que en este punto concreto no tiene nada que envidiar a las obras debidas a arquitectos. De una parte hay que destacar los detalles de cerámica que, a modo de alicatados, forran la parte inferior de las paredes del porche y el inglenook, puesto que fueron diseñados y materializados por Ruiz de Luna en $1929{ }^{34}$; de otra, las vidrieras de los tres ventanales de la escalera fueron realizadas en $1928{ }^{35}$ en los talleres bilbaínos de Vidrieras de Arte, por entonces sitos en La Salve ${ }^{36}$. También hay que

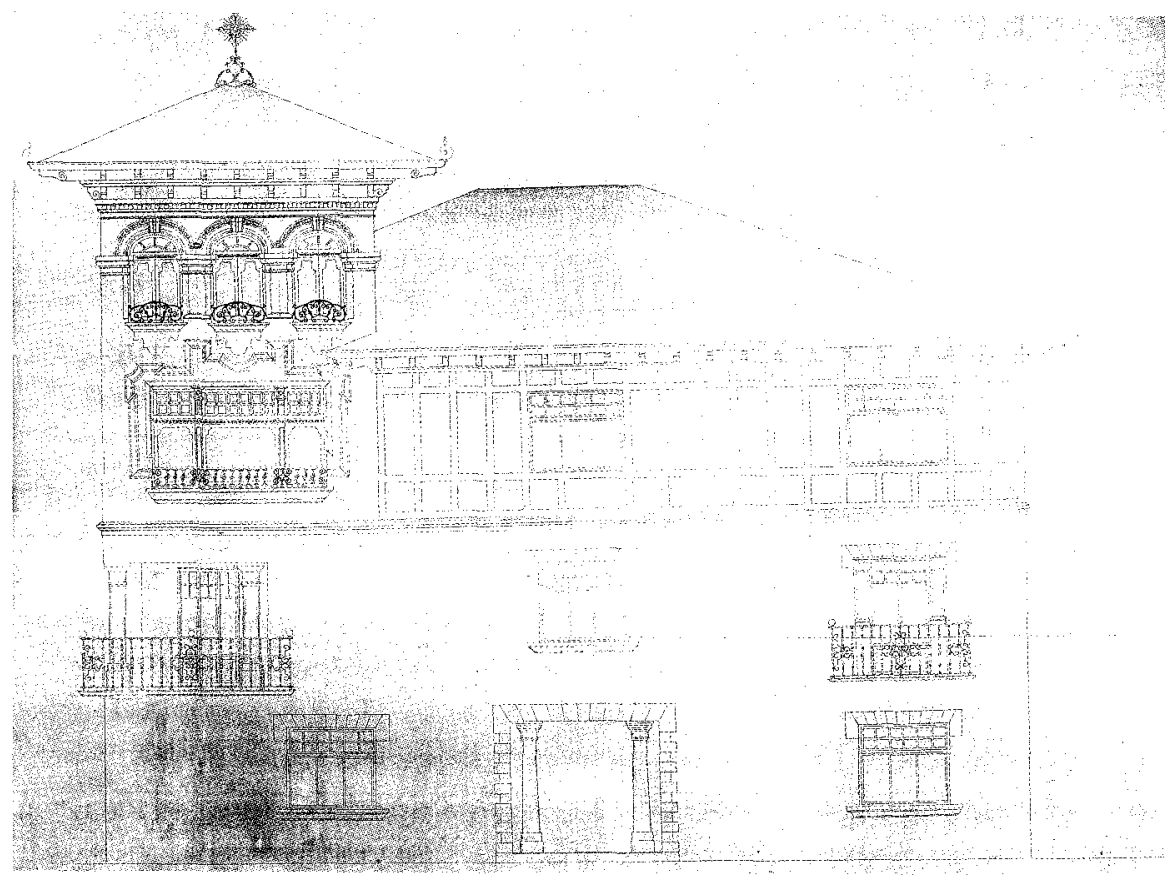

Fig. 5. Alzado de la fachada principal de la casa de la familia Hierro.

34 Esta fecha aparece, junto con la firma de Ruiz de Luna, en los frisos que decoran la zona de la chimenea del hall.

35 Esta fecha aparece en las vidrieras del ventanal del último cuerpo de la escalera.

36 Así consta en la vidriera, que repoducimos en este artículo, que decora el segundo cuerpo de la escalera. 
destacar la inclusion de pintura mural en el hall, la calidad de las labores de ebanistería y la diversidad de las soluciones decorativas de los techos de las dependencias de recibo.

Por lo que se refiere a la cerámica, la inclusión de diseños exclusivos de Ruiz de Luna es una de las muchas cuestiones de interés que encierra la casa de los Hierro. Juan Ruiz de Luna, nacido en 1863, fue junto con Enrique Guijo el responsable de la revitalización de la cerámica de Talavera a principios del siglo $x x$. Su obra, presidida por un denodado esfuerzo por recuperar las técnicas tradicionales talaveranas, se caracterizó por un extraordinario conservadurismo en lo referente a la iconografía ${ }^{37}$. En este sentido, las paredes del porche de la casa de Sopuerta están revestidas con paneles con los tonos azul y amarillo típicos de esa cerámica, que alternan en los fondos y en los motivos ornamentales. Estos están presididos por cartelas ovales -en una de las cuales figura la firma de Ruiz de Luna-, enmarcadas por abundantes decoraciones curvilíneas y vegetales. Algunas composiciones, en las que también hay clasicistas putti, tienen una curiosa tonalidad azul, que se aparta de las gamas habituales en las obras del ceramista toledano, que sin embargo las empleó por estas mismas fechas en otros edificios. Este es el caso de los frisos que decoran la fachada del inmueble de la madrileña calle de San Bernardo n. ${ }^{\circ} 112$, proyectado por el arquitecto José Antonio de Agreda en $1927^{38}$. En cuanto al hall, las paredes del inglenook también tienen revestimientos cerámicos, en los que sobre un fondo amarillo destacan dos escenas goyescas con tipos populares - muy acordes con el gusto castizo del ceramistaConcretamente reproducen los cartones para tapices $L a$ vendimia, también conocido como El otoño, (1786-1787) y El pelele (1791), encuadrados por paneles rectangulares, en los que, al igual que en las grecas y demás motivos que completan la composición, domina el color azul. Las olambrillas que salpican el solado de esta zona de la casa también debieron salir del taller de Ruiz de Luna, puesto que su cuidado diseño se aleja de lo usual en las piezas seriadas. Lamentablemente, estas últimas, a diferencia del resto de los detalles cerámicos del porche y el hall, están muy deterioradas.

La presencia de diseños exclusivos de Ruiz de Luna en el interior de esta residencia no fue algo excepcional, ya que si bien la mayor parte de su producción estuvo destinada a su aplicación a las fachadas de los edificios, en los que de ordinario resaltaban las líneas maestras de los mismos,

37 En este sentido, vid. PERLA, A.: Cerámica aplicada en la arquitectura madrileña. Comunidad de Madrid. Madrid, 1988, págs. 105 y ss.

38 Ibídem, págs. 123 y 133. 


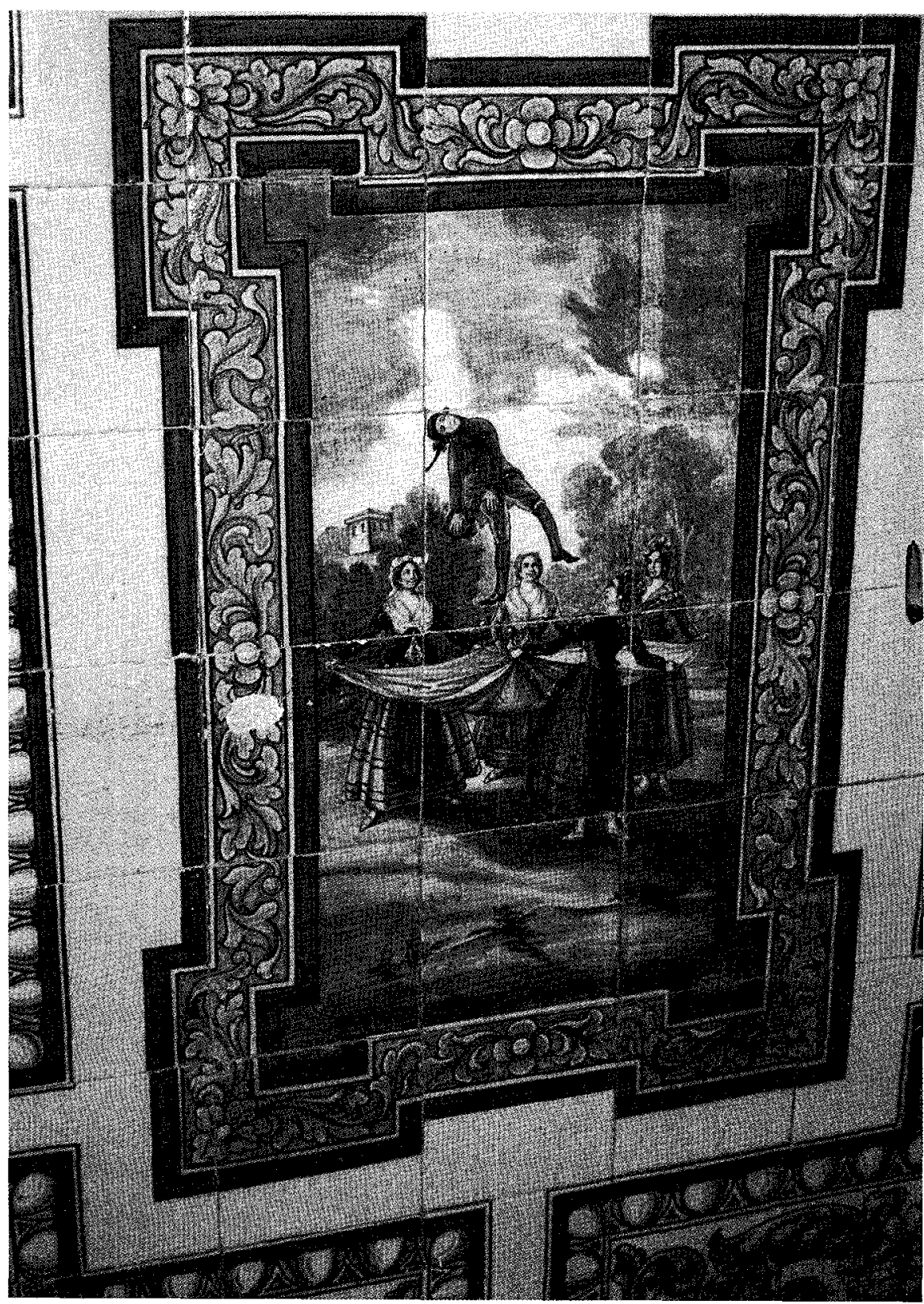

Fig. 6. Detalle de la decoración cerámica del inglenook de la casa de la familia Hierro. Diseño de Ruiz de Luna. 
también realizó diseños para interiores. Respecto a esta última cuestión cabe citar su participación en la decoración de la casa principal de la dehesa salmantina de Villoria de Buenamadre, proyectada por el arquitecto Joaquín de Vargas en los años veinte, donde hay chimeneas, alféizares, olambrillas, frisos. etc. salidos de este alfar talaverano ${ }^{39}$.

En cuanto a las vidrieras, decoran los tres ventanales de la escalera. Ya hemos dicho que salieron de los talleres de Vidrieras de Arte, establecimiento, fundado en Bilbao en 1917 por Isidoro Delclaux, Luis Lerchundi ${ }^{40}$ y Félix Cañada, que muy pronto adquirió prestigio, pues recibió un gran número de encargos tanto en el ámbito público como en el privado ya en los años veinte ${ }^{41}$. Dentro de estos últimos se sitúan los vitrales de esta casa de los Hierro-San Martín ${ }^{42}$, el de la planta baja tiene

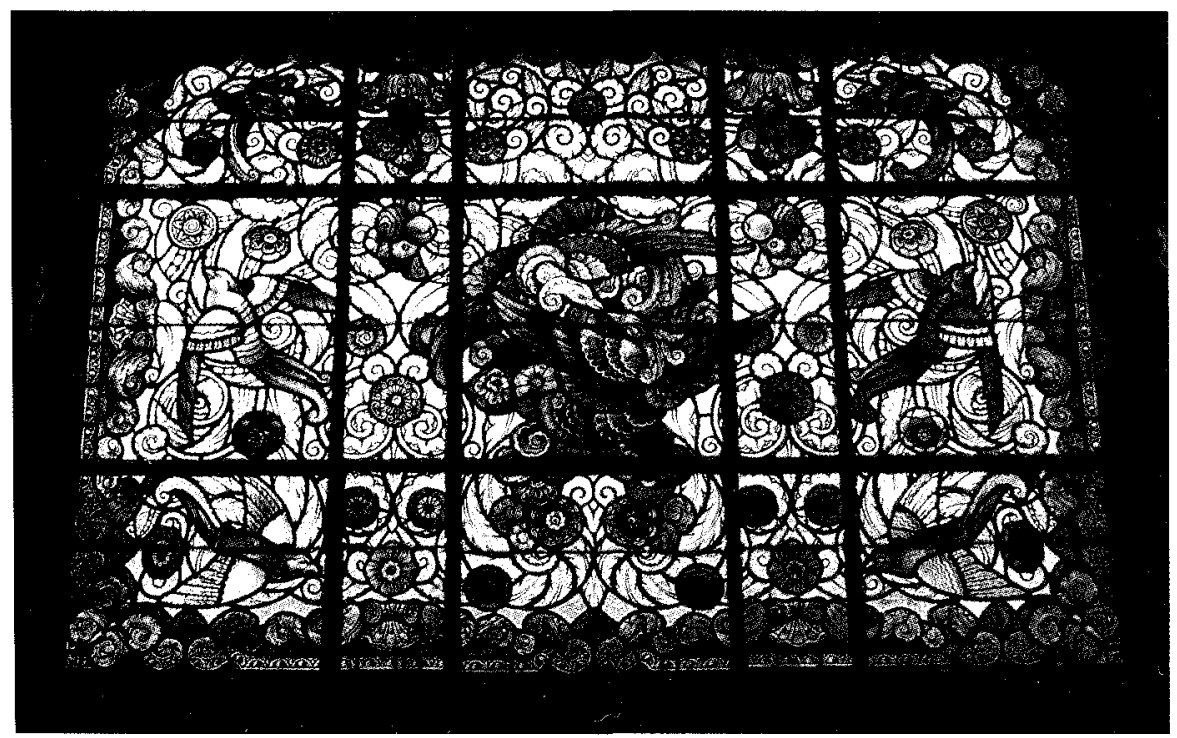

Fig. 7. Vidriera de la escalera de la casa de la familia Hierro.

39 Nieto González, J.R. y Paliza Monduate, M. T.: La arquitectura en las dehesas de Castilla y León. Junta de Castilla y León. Albacete, 1998, págs. 515-517.

40 Miguel de la Colina mantuvo estrechos lazos de amistad con Luis Lerchundi, delineante que fue responsable de las labores de diseño en la empresa Vidrieras de Arte.

41 Ibañez Gómez, M.; Torrecilla Gorbea, M. J. y Zabala Llanos, M.: Vidrieras de Arte S.A. setenta y cinco años de historia. En Un taller de luz. Vidrieras de Arte S.A. Diputación Foral de Bizkaia. Bilbao, 1994, págs. 39 y ss.

${ }_{42}$ Tenemos que hacer constar que fue el Sr. San Martín quien encargó a Vidrieras de Arte el diseño y la materialización de estos ventanales. (A.H.D.F.B.: Sección Vidrieras. Sig. VA 1048). 
como motivo principal una pequeña ermita ${ }^{43}$, que figura en medio de una cartela ovalada, rodeada por abundantes elementos curvos de tonos dorados. Esta pieza que aparece en el coronamiento del ventanal es, como hemos dicho, la más significativa de esta vidriera, que se completa con vidrios curvilíneos. Unos pájaros, a los que acompañan detalles florales, constituyen el núcleo de la del segundo piso ${ }^{44}$, mientras que la de la tercera planta es mucho más sencilla y convencional, circunstancia que delata el carácter secundario de las habitaciones de este piso, ya que este vitral está conformado por tres hojas, en las que predominan los cristales geométricos de distintos colores. Igualmente la sala del segundo piso cuenta con vidrios romboidales coloreados en la hoja superior del ventanal de guillotina, que suponemos procederían del mismo establecimiento bilbaíno. Tenemos constancia de que Vidrieras de Arte preparó para esta misma casa un boceto con un paisaje rural, que podría haber sido desestimado por los promotores, ya que no hay más estudios preparatorios del mismo ${ }^{45}$.

Goiko firma las pinturas murales del hall, realizadas al temple, cuyo estilo y temática entronca con la llamada pintura vasca de principios de siglo, de la que son representativas las obras de los Arrúe, los Zubiaurre, Arteta, etc. en cuanto a las formas planas, los colores vivos, los asuntos costumbristas con tipos populares vascos, etc. No obstante, la tendencia a decorar con pinturas la superficie alta de las paredes por encima del remate de los empanelados, que es de clara ascendencia británica, no fue muy seguida en el ámbito vizcaíno, por lo que la residencia de los Hierro resulta en este aspecto de especial interés. Las escenas que aparecen aquí representadas, que según consta en las mismas fueron pintadas en 1929, son una romería con txistularis y dantzaris junto a una ermita, juego de pelota en un frontón, juego de bolos y lanzamiento de jabalina, preparativos de una cacería y arrastre de piedra. Además por encima de la chimenea dos aldeanos rezan ante una hornacina con una imagen mariana, todo ello se recorta sobre un típico paisaje costero vásco, en el que destaca una pequeña iglesia. El conjunto está resuelto con armonia cromática entre las figuras y los fondos y gracia y habilidad para distribuir las distintas composiciones,

43 El diseño de esta vidriera y el protagonismo en la misma de esta construcción como motivo principal podía inducir a pensar que se tratara de algún edificio de especiales connotaciones para los promotores. En este sentido, podemos descartar que se trate de alguna de las ermitas existentes en el municipio de Sopuerta y sus alrededores.

44 Tenemos constancia de que Vidrieras de Arte elaboró al menos cuatro soluciones distintas para esta vidriera. Todas ellas tenían pájaros y flores como motivo principal. (A.H.D.F.B.: Sección Vidrieras. Sign. VA 0998).

45 A.H.D.F.B.: Sección Vidrieras. Sig. VA 1048. 


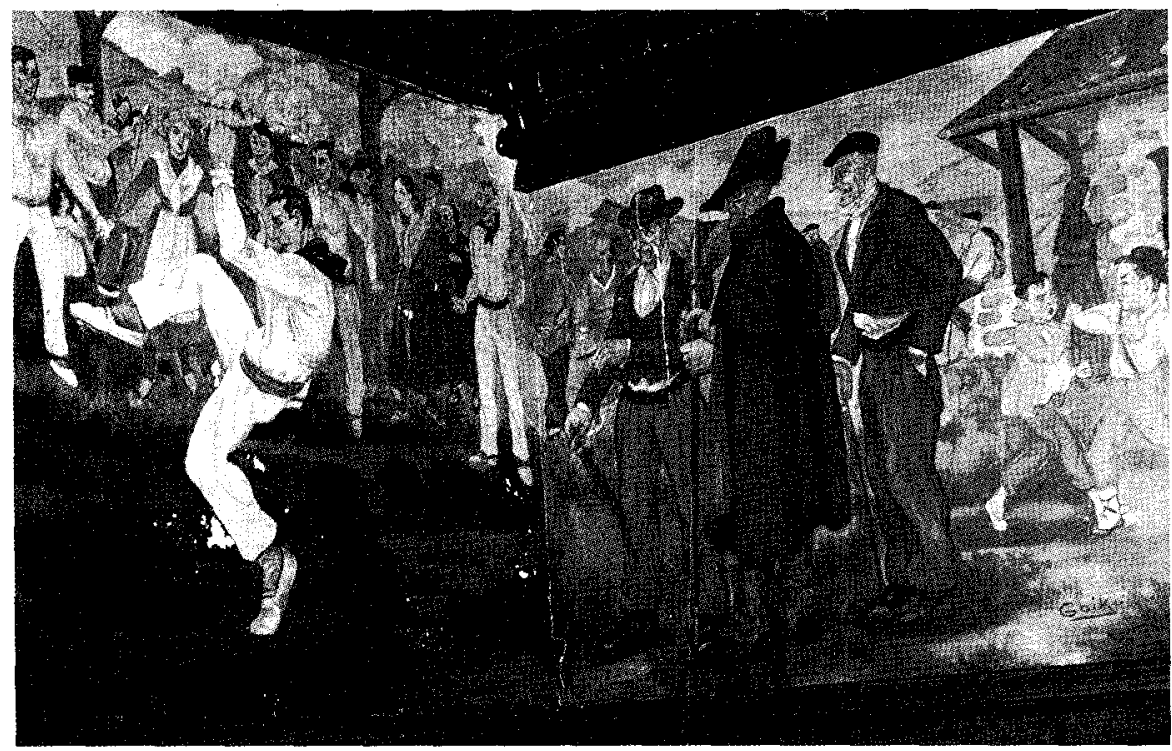

Fig. 8. Detalle del hall de la casa de la familia Hierro. Pinturas firmadas por Goiko.

que no dejan de tener cierto encanto infantil por la simplicidad de los volúmenes y la importancia del dibujo. Estos murales enlazan con el estilo del autor, uno de los mejores cartelistas vascos del siglo xx, que también destacó como dibujante e ilustrador ${ }^{46}$.

Las labores de ebanistería son soberbias. Fueron concebidas en su totalidad por Miguel de la Colina, que elaboró los correspondientes diseños ${ }^{47}$ y encontró aquí un campo de expansión para su particular afición a este tipo de trabajos, a la que ya nos referimos al glosar los aspectos biográficos del ingeniero. En este sentido son muchos los detalles reseñables, pues hay que aludir a las magníficas puertas casetonadas y los marcos con orejeras y distintos detalles de talla, la diversidad de los empanelados, que forran la parte baja de las paredes de las habitaciones nobles, incluso las contrahuellas de los peldaños de la escalera incorporan decoraciones talladas en la propia madera. Igualmente, tenemos constancia de que eran magníficos los solados de marquetería de las dependencias de recibo de la planta baja, que lamentablemenie no han llegado hasta nosotros.

46 Marrodan, M.A.: Diccionario de pintores vascos. (T. II). Ediciones Beramar. Bilbao, 1989, pág. 175.

47 A.P.J.C.M.: Planos varios s.c. 
Finalmente, las decoraciones de los techos también revisten interés, pues son distintas en todas las habitaciones de la planta baja. Predomina la tendencia a imitar distintos tipos de artesonados de madera con trabajos de escayola pintados, algo que fue muy frecuente en la época decimonónica y en las primeras décadas del xx. En menor medida el artífice hizo uso de molduras de escayola, que fueron escogidas para decorar el comedor. Otra cuestión a destacar es la simulación de sillería mediante pintura en las paredes del cuerpo de la escalera, que presenta forros de empanelados en la parte baja.

El jardín data en su totalidad del momento de la intervención de Miguel de la Colina en esta finca, ya que la primitiva edificación sólo contaba con prados y huertas. En este aspecto el ingeniero también demostró estar al día en estas cuestiones, ya que de una parte la casa está alejada de la portalada, que sirve de entrada noble al recinto y, de otra, el camino principal no desemboca directamente en la residencia, ya que ésta está ladeada respecto a la pequeña avenida. Todo ello tiene como principal función defender la privacidad de la casa, algo muy perseguido en el trazado de los jardines vizcaínos de ese momento, que, influidos por las modas británicas del siglo $X \mathrm{IX}{ }^{48}$, huían de las perspectivas enfáticas y trataban de preservar la vivienda de las miradas de extraños. Asimismo el predominio absoluto de las zonas de pradera y la importancia del arbolado, que incluye una gran variedad de especies (sequoias, palmeras, sauces, magnolios, etc.), en detrimento de un jardín regular de setos y parterres enlaza, al igual que la existencia de una pista de tenis, con las modas inglesas que, como queda dicho, tuvieron gran predicamento en Vizcaya. La portalada propiamente dicha consta de un pequeño tejado que protege las puertas de madera del acceso y está flanqueada por pilares de planta cuadrilonga, realizados con piedra arenisca y rematados por pináculos de aire escurialense ${ }^{49}$.

Unos años más tarde, Miguel de la Colina volvió a intervenir en la remodelación de otra casa en el mismio municipio. En este caso el comitente fue otro indiano Jose María Quintana Garay, que había hecho una gran fortuna en Méjico. A su regreso a España fijó su residencia en Madrid, pero decidió levantar una casa de veraneo en la localidad natal. A tal efecto en julio de 1933 adquirió un terreno con una vivienda a los hermanos Conde

48 En este sentido vid. Pal.1Za Monduate, M: La importancia de la arquitectura inglesa del siglo xIx y su influencia en Vizcaya. Kobie (Bilbao). N. ${ }^{\circ} 4$ (1987), págs. 65-100.

49 En la actualidad esta casa acoge la Residencia Sopuerta de la Asociación Gorabide, dedicada a la atención de minusválidos psíquicos. Desde estas líneas agradezco a Begoña Aguirre, directora de este centro, su amable colaboración a la hora de elaborar este artículo. 
Gómez del Olmo, que a su vez lo habían heredado de Pablo Puerto. Por las mismas fechas compró otra parcela aneja a la anterior a la familia Quintana Setién ${ }^{50}$. Estas fincas, situadas en la zona de La Baluga, pasaron a constituir por agregación la propiedad de José María Quintana, quien de forma inmediata decidió reformar y ampliar la vivienda ${ }^{51}$ para lo cual contó, como hemos anunciado, con la participación del ingeniero que nos ocupa en lo relativo a la concepción del proyecto y la dirección de obra.

El edificio existente era una pequeña construcción cúbica y regular, cuyo trazado y decoración interior fueron totalmente transformados, mientras que su fisonomía exterior varió notablemente al disponer Miguel de la Colina un torreón a cada lado del núcleo primigenio, mientras que el mirador que decoraba la fachada principal fue sustituido por el actual, que es de obra y está alineado con el porche que protege la entrada noble de la residencia. La intervención del ingeniero recuerda desde algunos puntos lo hecho en la casa de los Hierro, ya estudiada, si bien en el caso que nos ocupa la estructura de la primitiva vivienda es fácilmente reconocible entre los cuerpos torreados que la escoltan, dado el sencillo formato y el reducido tamaño de los huecos.

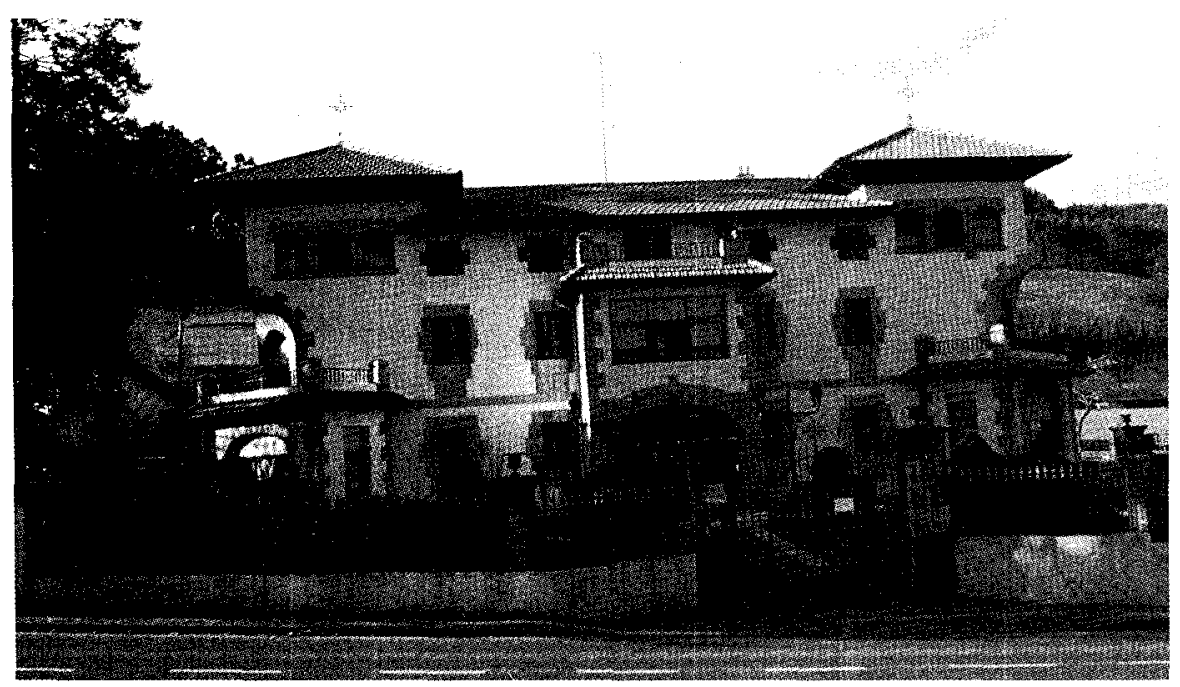

Fig. 9. Fachada principal de la casa de la familia Quintana.

50 A.R.P.B.: Libro 469. Sopuerta, fs. 90 v-92 v.

51 En la actualidad este inmueble alberga la residencia de ancianos Bizi-Berria, a cuyos responsables agradezco las facilidades que me han brindado para realizar la presente investigación. 
Así, la concepción espacial remite al planteamiento desarrollado en los años veinte, sobre todo en lo relativo a la configuración del hall, que en este caso es una habitación aún más espaciosa y que, al igual que en el ejemplo anterior, tiene inglenook y acoge el arranque de la escalera, al tiempo que, según la tradición inglesa, aparte de dar paso a las zonas de servicio y recibo, servía de lugar de estar. De hecho el edificio conserva parte del mobiliario original que ratifica que éste era en buena medida el uso de esta dependencia, que estaba flanqueada por el comedor principal y la sala de billar, igualmente dotados de una zona de estar en el sector de los cuerpos torreados del edificio. Por lo demás estas tres habitaciones cuentan con ventanas rasgadas en la fachada noble de la residencia. La capilla, el despacho y la cocina y sus anejos completan la planta baja, mientras que el primer piso correspondía a la zona de noche.

El alzado entronca claramente con el estilo regionalista montañés, sobre todo en lo relativo a la silueta de los torreones, que incorporan vanos en ángulo, galerías tripartitas y alero de gran vuelo, todo ello inherente a la arquitectura promovida por Leonardo Rucabado en la segunda década del siglo xx. El comedido repertorio ornamental, que aún resulta más escueto en el caso de las fachadas laterales y zaguera, puede ser imputable a la fecha tardía del proyecto. En contraposición, la configuración de un frente simétrico como consecuencia de la introducción de dos cuerpos torreados idénticos resulta más anómala, puesto que, aunque con cierta frecuencia aparecieron en casas dobles, su presencia en viviendas unifamiliares es ciertamente inusual y tal vez se deba a la condición de ingeniero del artífi$c e$, quien al igual que sus colegas pone de manifiesto en estas obras ciertas limitaciones a nivel de composición respecto a los cánones establecidos. Seguramente se debían a algunas lagunas presentes en este punto específico en la formación de los ingenieros frente a la de los arquitectos. Estos últimos además se beneficiaban de los conocimientos derivados de la experiencia en este campo concreto y de la práctica continuada de su profesión. En este asunto discrepo de otros autores que han recogido datos sobre viviendas concebidas por ingenieros, ya que, aunque no dudo de que haya obras paradigmáticas firmadas por estos profesionales, en lo relativo al ámbito encartado todos los ejemplos conocidos hasta ahora adolecen de alguna carencia o limitación, que en algunos ejemplos atañen incluso a la decoración de interiores.

Hay un hecho ciertamente significativo y destacable en lo referente al modo de preparar y materializar estos diseños por parte del técnico que nos ocupa, puesto que se conserva una maqueta de los huecos, dispuestos en ángulo, correspondientes al primer piso de las torres. Este modelo fue realizado personalmente por el propio Miguel de la Colina, quien de 


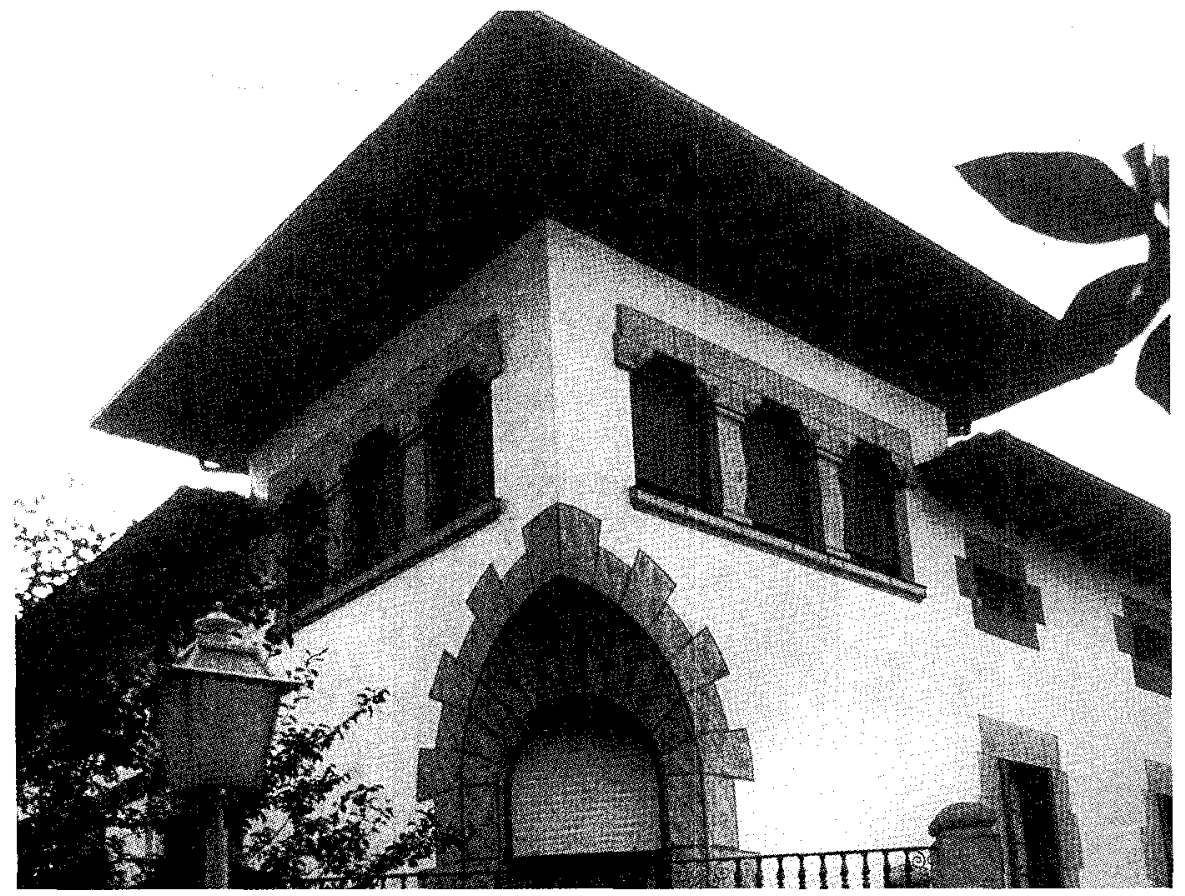

Fig. 10. Detalle de una de las torres angulares de la casa de la familia Quintana.

este modo puso en evidencia el cuidado y la minuciosidad con la que se enfrentaba a las tareas arquitectónicas. Por lo demás, la presencia de este tipo de vanos de alguna manera enlaza con lo hecho en la residencia de los Hierro, donde el ingeniero dispuso una terraza en ángulo, delimitada por sobrias columnas. Esta coincidencia puede demostrar cierta querencia del personaje que nos ocupa hacia estos huecos, propios de la arquitectura renacentista e incorporados por Rucabado a su repertorio.

En líneas generales, la decoración interior es menos espectacular que en el ejemplo anterior, a excepción de la escalera que presenta idéntica concepción, ya que, de una parte, las paredes del inglenook están revestidas con azulejos de fabricación seriada y, de otra, el diseño de los suelos, las puertas, los empanelados y los techos es mucho más comedido que en la casa vecina de los Hierro. La presencia de zapatas avolutadas por encima de los pilares, que interceptan el hall, entronca con modelos usuales en la decoración de interiores del regionalismo montañés. En contraposición, las vidrieras tienen un mayor protagonismo en este edificio que en el proyectado en los años veinte, algunos de los diseños (ventanas 
y puerta de la capilla ${ }^{52}$ y hall) incluyen motivos historicistas, mientras que los vitrales de la escalera, el comedor y la sala de billar cuentan con detalles fabriles, que enlazarían con los diseños de actividades industriales,

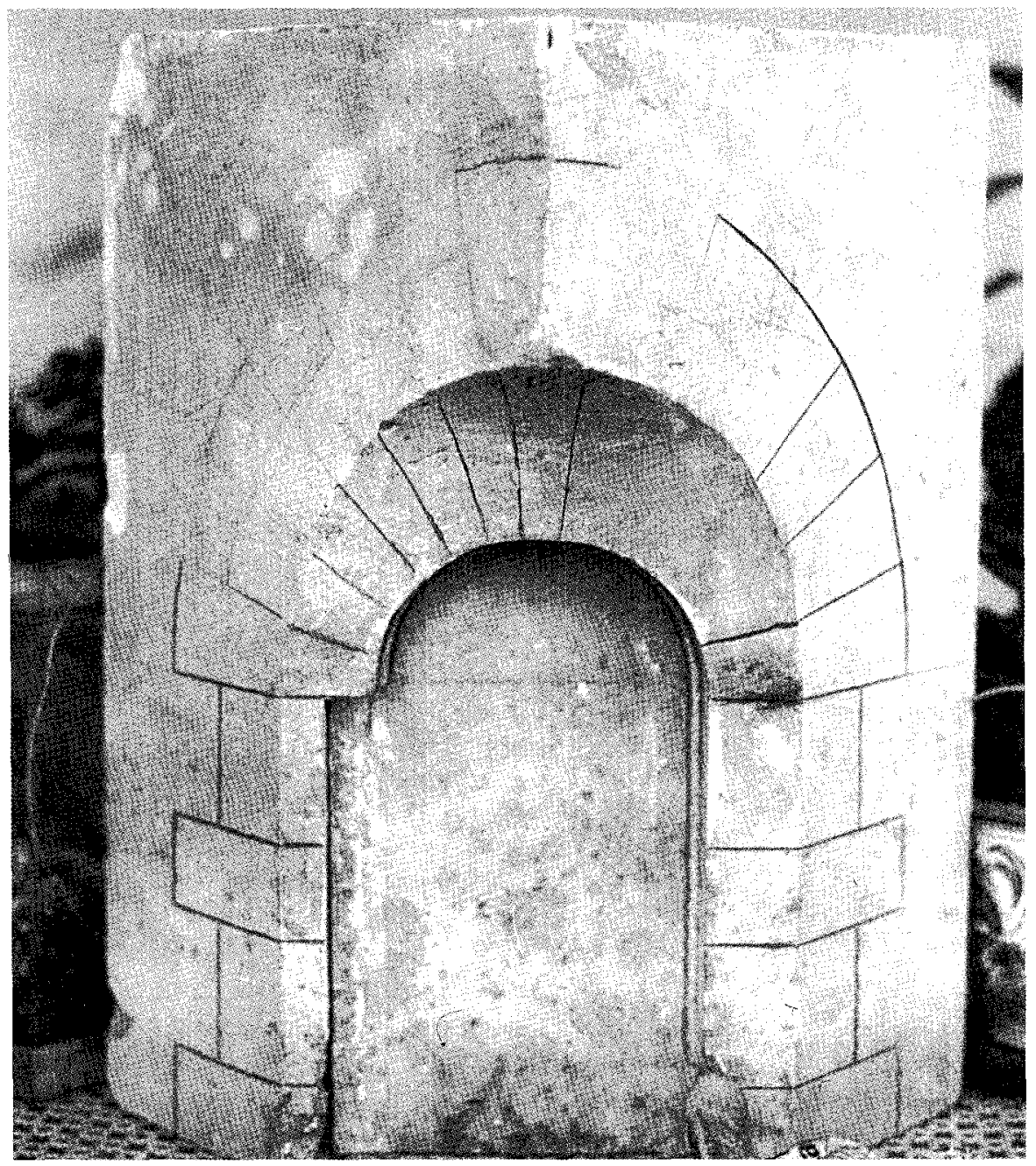

Fig. 11. Maqueta realizada por el propio Miguel de la Colina para las ventanas en ángulo de la casa de la familia Quintana.

52 En las vidrieras de la capilla figura la firma Vidrieras de Arte, cuyo taller por entonces ya estaba establecido en la bilbaína calle Espartero. 
que fueron recurrentes en las obras salidas de los talleres de Vidrieras de Arte, a mediados de siglo ${ }^{53}$. La circunstancia de que ambas residencias cuenten con vidrieras artísticas, que en el caso de la vivienda de los Quintana están presentes en la casi totalidad de las dependencias principales, ratificaría el atractivo que tenían para Miguel de la Colina, los interiores de luces tamizadas y coloreadas y los propios vitrales como elemento ornamental. De todos modos, la estrecha relación de amistad que tuvieron el ingeniero y Luis Lerchundi, uno de los fundadores de Vidrieras de Arte, pudo influir en esta predilección.

Conviene destacar la abundancia de tapices en la decoración de las habitaciones de recibo, algo que no fue frecuente en las residencias vizcaínas de la época. Estas piezas, que aún cuelgan de su emplazamiento original, son de calidad y están presididas por escenas goyescas, de cacería o religiosas, en alguna de las cuales figura la firma de E. Escudero. Por lo demás, la capilla conserva un retablo neogótico, que también data de la época de construcción del inmueble.

José María Quintana también promovió la construcción de un garaje y un gallinero, que subsisten en la actualidad. Ambos debieron correr a cargo del propio Colina, quien, como veremos más adelante, también proyectó años más tarde un frontón. En contraposición, sólo modificó levemente el trazado del jardín ${ }^{54}$, ya que la casa primigenia estaba toda ella cercada de paredes que contiene varios árboles frutales, jardín con verja de hierro y otros adornos ${ }^{55}$. En este aspecto, lo más espectacular del recinto son las dos pérgolas, dispuestas en la parte delantera lindante con la carretera.

No encontramos ecos racionalistas en ninguna de estas dos residencias de Sopuerta, salvo tal vez ciertos aspectos del diseño de algunas vidrieras de la casa Quintana, aunque todo induce a concluir que éstos fueron ideados por el personal de Vidrieras de Arte. La fecha de construcción de ambos edificios en torno a 1930 coincide con el momento en que aquellas formas empezaron a tener cierta importancia en nuestro país. No obstante y en líneas generales, la tipología de la vivienda unifamiliar, debido en parte al tradicionalismo de los propios promotores, mostró un gran conservadurismo, que retrasó notablemente la incidencia de ese estilo en este tipo de edificios. En este sentido, Miguel de la Colina siguió pautas similares a las

53 Ibáñez Gómez, M.; Torrecilla Gorbea, M. J. y Zabala llanos, M.: Op. cit., pág. 61.

54 Así lo ratifica la documentación conservada en el correspondiente Registro de la Propiedad y el testimonio de testigos presenciales de la construcción. En este sentido, agradezco la inestimable y constante colaboración de Nieves Alonso Nocedal.

55 A.R.P.B.: Libro 529. Sopuerta, f. 142. 


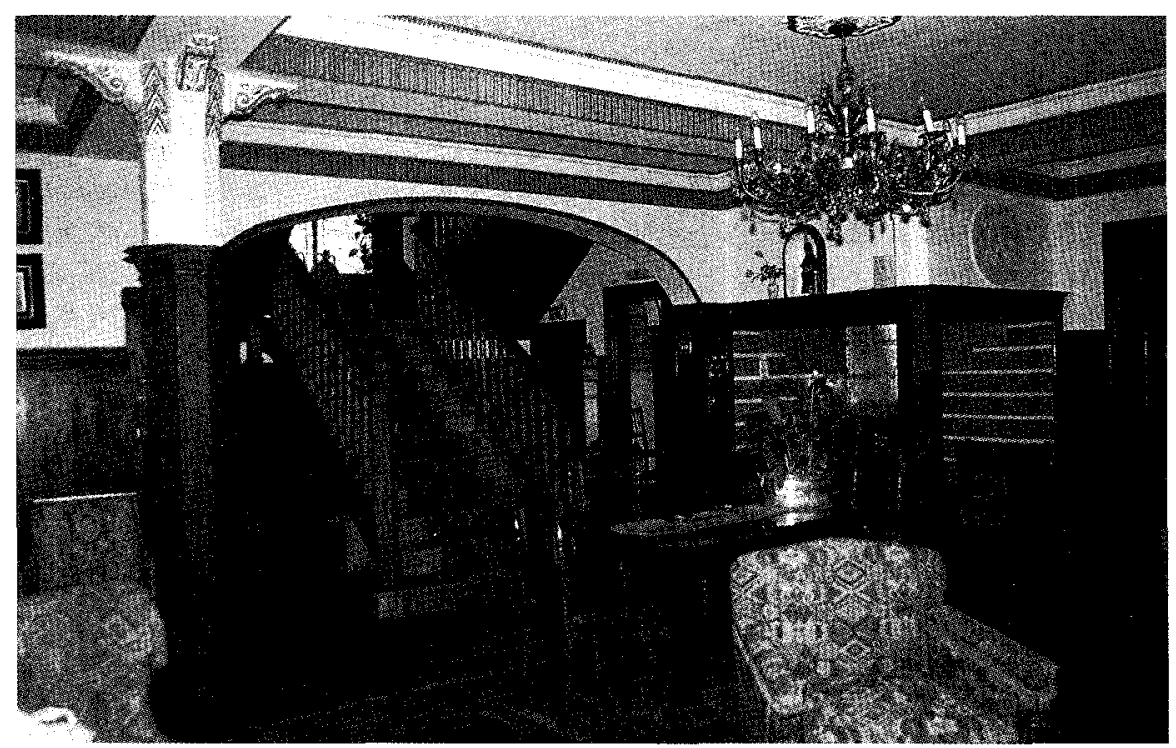

Fig. 12. Hall de la casa de la familia Quintana.

de la mayoría de los arquitectos, pese a que en primera instancia su condición de ingeniero permitiera suponer un mayor interés por las soluciones desornamentadas del racionalismo.

Tenemos también constancia de que en los duros años de la Posguerra el personaje que nos ocupa elaboró un proyecto de Frontón barato, susceptible de levantarse en distintos emplazamientos (colegios modestos, pequeños municipios, sociedades deportivas de escasos medios, etc), en el que aquilató al máximo lo relativo al presupuesto, dada la precaria situación económica de la época, que obligaba a prescindir en la mayoría de las ocasiones de la posibilidad de construir frontones de piedra de sillería.

Esta preocupación se debía tanto a su afición a este deporte como a su creencia en los beneficios que su práctica aportaba al espíritu y a la formación de las personas, puesto que al respecto decía Es indudable que bajo el punto de vista del ejercicio físico, no hay deporte como la pelota; pero ademas es un juego noble por naturaleza; ya que en el, no cabe ni el juego sucio; ni la inutilización intencionada del contrario como vemos con harta frecuencia en el fut-bol; ni el regar tras si la carretera con tachuelas para que pinche el que viene detras, como en las carreras ciclistas ni los golpes bajos como en el boxeo. $Y$ esto tiene gran importancia en la educación del individuo; porque el que se acostumbra a 
jugar sucio, también lo hara en las otras relaciones que exige la lucha por la vida... Así las cosas, ideó soluciones que preveían la utilización de ladrillo o de bloques prefabricados de cemento, que abarataban notablemente los presupuestos. Preocupado por la seguridad de sus propuestas en lo relativo a la estabilidad y resistencia al viento, hizo consultas al instituto de Cálculo del Consejo Superior de Investigaciones Científicas, que informó favorablemente. Finalmente, en 1952, Angel Quintana Zavala, hijo del promotor de la residencia reformada en los años treinta, le encargó un frontón de estas características que aún subsiste en el jardín de la citada casa ${ }^{56}$.

De la Colina también fue el artífice del proyecto del panteón de la familia Quintana en el cementerio de San Cristóbal del barrio soportano de La Baluga ${ }^{57}$, materializado por Anastasio de Amesti. Consta de una gran cripta y un muro testero, presidido por un gigantesco Cristo en la cruz. Es una sepultura al uso de los modelos imperantes en la arquitectura funeraria del momento, cuya severidad y monumentalidad tal vez delatan la condición de ingeniero de su autor.

En otro orden de cosas, su trabajo como boticario no fue del todo convencional, en el sentido de que no se limitó a atender únicamente la elaboración de fórmulas magistrales y asumir la responsabilidad de la venta de medicamentos, ya que tenemos constancia de que llegó a patentar jurito con un veterinario un producto destinado al ganado vacuno, al que denominaron Expeleparia, que facilitaba la expulsión de las parias tras los partos ${ }^{58}$. Asimismo, en 1958 obtuvó el primer Premio Ricardo Angulo, creado por el Colegio de Farmacéuticos de Vizcaya para reconocer la labor científica de los inspectores farmacéuticos municipales, que anualmente debían elaborar una memoria en la que recogían las actividades desarrolladas durante el período ${ }^{59}$. En 1963, recibió la medalla de plata del Colegio de Farmacéuticos junto con el resto de colegiados de más de setenta años de edad y veinticinco años de ejercicio de la profesión ${ }^{60}$.

La dedicación prioritaria a las labores farmacéuticas y las intervenciones ocasionales en el campo de la arquitectura no impidieron que realizara también puntuales aportaciones al mundo de la ingeniería. Numerosos

56 A.P.J.C.M.: Documentos varios S.C.

57 Ibídem: Planos varios s.c.

58 Saratxaga Garal, A.: Op. cit., pág. 337.

59 MuñIz Petralanda, J.: Ecos de la guerra y recuperación 1939-1967. En Cien años velando por la salud de los vizcaínos. Colegio Oficial de Farmacéuticos de Bizkaia y Banco Atlántico. Bilbao, 1998, págs. 114 y 115.

60 lbídem, pág. 119. 
títulos de esta materia de autores tales como Hütte, C. Bach, A. Ledebur, Gerard, C. Kersten, S. Crivillés, Marvá, Oliveras, A. Flamant, Fournier, E. Gallego Ramos, E. Villar Peralta, etc., así como las suscripciones a las revistas Dyna, El ingeniero y contratista, Hormigón y acero, etc. nutrían la biblioteca ${ }^{61}$ de Colina, que, a juzgar por las fechas de edición de varios volúmenes de la misma se enriqueció con libros de temas propios de la ingeniería a lo largo de los años veinte y treinta, circunstancia que ratificaría que el interés del personaje que nos ocupa por esta disciplina continuó vivo, aunque no desempeñara esta profesión de forma continuada. Veremos cómo en los años veinte proyectó una traída de aguas para el municipio de Sopuerta, mientras que en la difícil época de la posguerra inscribió en el Registro de la Propiedad Industrial un proyecto de Nuevo sistema de construcción de vigas de hormigón armado, con el que intentaba paliar el problema derivado de la necesidad de madera para el proceso del encofrado del hormigón armado, dado que este material escaseaba en España por entonces y que su importación elevaba notablemente el costo de la producción ${ }^{62}$.

Mención aparte merece su vinculación al ayuntamiento de Sopuerta tanto en su condición de concejal como de alcalde. No fueron ni la vocación ni el interés por la política, los que le llevaron a ocupar estos cargos, ya que en ambas ocasiones le vinieron impuestos por las circunstancias o instancias superiores. En la sesión extraordinaria del pleno municipal, celebrada el once de marzo de 1924, Miguel de la Colina Puyol fue nombrado concejal como consecuencia de una normativa, promulgada por el Gobierno del General Primo de Rivera, que prohibía que ocuparan cargos municipales individuos que no supieran leer y escribir. La entrada en vigor de esta reglamentación supuso que tres ediles abandonaran sus puestos en el consistorio soportano ${ }^{63}$. Dadas las especiales condiciones de Sopuerta en aquellos años, en los que escaseaban las personas ilustradas, la designación del ingeniero que nos ocupa fue casi obligada.

En esta época su principal contribución en beneficio del pueblo fue la intervención en favor de la mejora del abastecimiento de agua, ya que el veinticuatro de septiembre de 1924 Colina denunció ante el consistorio

\footnotetext{
61 De esta biblioteca también formaba parte un ejemplar de Las casas vascas, la obra de Joaquín de Yrizar editada en 1929. Entre sus páginas aún se conservan numerosos papeles, en los que Colina dibujo croquis y distintos detalles de arquitecturas.

62 A.P.J.G.M.: Documentos varios s.c.

63 A.M.S.: Libro de Actas Municipales que da comienzo el 4 de mayo de 1922 y termina en 30 de marzo de 1924 , f. 387 .
} 
municipal la intención del Ayuntamiento de Portugalete de encauzar en su provecho los manantiales soportanos de Saldamando y Tremoral, que previamente habían sido denunciados y reclamados ante el Gobierno Civil de Vizcaya por Sopuerta con la intención de mejorar el aprovisionamiento de sus vecinos ${ }^{64}$. Las pretensiones de los portugalujos no prosperaron, ya que dos años más tarde, en julio de 1926, el propio Colina elaboró un Proyecto de Aprovechamiento de agua de varios manantiales de las laderas del barranco de Tremoral, que según argumentaba en la correspondiente memoria surtiría del agua indispensable a todos los barrios del municipio. El diecisiete de septiembre del mismo año, Eduardo Anduiza, ex-profesor de Hidráulica de la Escuela de Ingenieros Industriales de Bilbao, informó favorablemente sobre la solución ideada por el personaje que nos ocupa ${ }^{65}$. Consta que el artífice del proyecto no cobró honorarios por su trabajo, ya que consideraba estas actividades como una obligación más del cargo de Inspector Farmaceutico Municipal, ${ }^{66}$ que desempeñaba en función de su condición de titular de la botica de Sopuerta, lo que ratificaría su filantropía con respecto al terruño natal.

Desconocemos la fecha exacta en la que Colina cesó como concejal, ya que no se conservan los libros de actas municipales correspondientes al período 1924-1931, pero parece que en septiembre de 1926 ya no era edil ${ }^{67}$. Posteriormente ultimó un Proyecto de mejora del abastecimiento de aguas de Tremoral, firmado en mayo de $1934{ }^{68}$.

Años más tarde, en el pleno municipal celebrado el diecinueve de septiembre de 1944 , Colina fue nombrado alcalde ${ }^{69}$, cargo que desempeñó hasta el trece de julio de 1946, fecha en la que manifestó que no podía cumplir con sus obligaciones al frente del ayuntamiento, puesto que su auxiliar de farmacia iba a estar de vacaciones hasta mediados de septiembre, de modo que él tenía que atender el establecimiento y realizar la toma de aguas para los análisis correspondientes respecto a la potabilidad de la misma ${ }^{70}$. Sin embargo, no volvió a incorporarse a su puesto de

64 Ibídem: Libro de Borradores de Actas de Plenos que da comienzo el 21-06-1924 y finaliza 9-04-1931, f. 14.

65 A.P.J.C.M.: Planos varios s.C.

66 De la Colina, M.: Memoria de la inspección farmacéutica..., pág. 22.

67 A.M.S.: Libro de Borradores de Actas de Plenos que da comienzo el 21-06-1924 y finaliza 9-04-1931, f. 104.

6e A.P.J.C.M.: Planos varios s.c.

69 A.M.S.: Libro de Actas de Pleno del Ayuntamiento de Sopuerta que comienza 5-08-1940 y termina 16-03-1946, is. 177 y $177 \mathrm{v}$.

70 Ibídem: Libro de Actas del Ayuntamiento de Sopuerta que da principio en 31 de marzo de 1946 y termina en 10 de abril de 1954, f. 25. 
alcalde, de modo que fue cesado el treinta de septiembre del mismo año ${ }^{71}$. Su acceso a la alcaldía, al igual que había ocurrido en los años veinte, no fue consecuencia de una decisión voluntaria, antes al contrario le vino impuesta por designación del Gobernador Civil. La documentación municipal ratifica que Colina se resistió a este nombramiento y que quiso escoger personalmente sus colaboradores en las tareas municipales, aspiración que no le fue permitida ${ }^{72}$. En su discurso de toma de posesión se refirió a la alcaldía en los siguientes términos puesto que yo ni he buscado, ni he deseado, ni he merecido... Una vez aquí, yo pongo toda mi mejor voluntad al servicio de todos, absolutamente de todos los vecinos del pueblo, sin distinción de colores ni matices, porque para mi ante la ley, todos somos iguales y ante Dios, todos hermanos redimidos por Cristo. Asimismo, en esta declaración de intenciones anunció que llevaría a cabo una gestión austera, porque la precaria situación de las arcas municipales no permitía otra opción ${ }^{73}$.

A esta breve etapa al frente de la alcaldía de Sopuerta corresponden los planos de urbanización de los tres cementerios de la localidad (La Baluga, Mercadillo y Carral), firmados por el propio ingeniero en septiembre de 1945, que tenían por objeto la distribución regularizada de los terrenos de las futuras concesiones de sepulturas ${ }^{74}$.

Durante los dífiles tiempos de la Guerra Civil y los primeros años de la Posguerra, Miguel de la Colina dio buena prueba de la rectitud de sus principios y de su integridad al negarse a informar sobre actuaciones concretas o tendencias políticas de convecinos, a los que el personaje que nos ocupa consideraba por encima de todo personas de bien. Esta negativa le ocasionó más de un problema, pues, según consta documentalmente, hubo intentos de depurarle políticamente ${ }^{75}$.

Tras una vida larga y de intensa dedicación al trabajo, el veintiocho de diciembre de 1976, Miguel de la Colina falleció de forma repentina en la casa familiar de Sopuerta, rodeado de sus cuatro nietos, dos de los cuales continuan la tradicional vinculación familiar a la farmacia, mientras que una tercera perpetúa la que fuera primera vocación del protagonista de este artículo, pues ejerce como ingeniero industrial.

\footnotetext{
lbídem, f. 50.

72 Ibídem: Libro de Actas de Pleno del Ayuntamiento de Sopuerta que comienza 5-08-1940 y termina $16-03-1946$, fs. 177 y $177 \mathrm{v}$.

73 Jbídem, fs. 177-179.

74 A.P.J.C.M.: Planos varios S.c.

75 Ibídem: Documentos varios S.c.
} 
ABREVIATURAS:

A.G.A.E.A.H.: Archivo General de la Administración Española de Alcalá de Henares.

A.H.D.F.B.: Archivo Histórico de la Diputación Foral de Bizkaia.

A.M.S.: Archivo Municipal de Sopuerta.

A.P.J.C.M.: Archivo Particular de Javier de la Colina Menéndez.

A.R.P.B.: Archivo del Registro de la Propiedad de Balmaseda. 